\title{
SIERRA MORENA COMO ESPACIO PROTEGIDO: DEL OLVIDO TRADICIONAL AL INTERÉS RECIENTE ${ }^{1}$
}

\author{
Alfonso Mulero Mendigorri \\ Departamento de Geografía y Ciencias del Territorio. Universidad de Córdoba
}

\section{RESUMEN}

En este artículo se analiza el papel que la Sierra Morena andaluza desempeña en las políticas de conservación de espacios naturales. En la primera parte se describen las principales iniciativas emprendidas en esta unidad geográfica, destacándose los criterios seguidos y las figuras de protección empleadas; en segundo lugar, se señalan las dificultades y limitaciones de la actual red de áreas protegidas, y, por último, se indican las perspectivas inmediatas que ha generado la Directiva Hábitats de la Unión Europea.

Palabras clave: Sierra Morena, espacios naturales protegidos, medio ambiente, Directiva Hábitats.

\begin{abstract}
The article analyzes the role that Andalusian «Sierra Morena» plays in natural paces conservation politics. In the first part it is described the main initiatives to this geographical unit, emphasizing the models of protection and some of the attitudes that there has been adopted. The second part of the article points on several limitations and difficulties in the actual net of protected areas; finally, I point out some of the immediate perspectives generated by European Community «Directiva Habitats».
\end{abstract}

Key words: Sierra Morena, natural protected areas, environment, «Directiva Habitats».

1 Trabajo realizado en el contexto del proyecto de investigación «Propiedad, actividad agraria y ocio en los Parques Naturales de Sierra Morena» (Secretaría de Estado de Universidades, Investigación y Desarrollo, 1999). 


\section{Introducción}

En sentido estricto Sierra Morena no ha contado en las políticas de protección de espacios naturales hasta la década de los ochenta. Si prescindimos de iniciativas colaterales —Catálogo de Montes de Utilidad Pública de 1857, Inventario de Paisajes Sobresalientes de 1917, Inventario Abierto de Espacios Naturales de Protección Especial de 1975, etc.- - y nos centramos únicamente en las dirigidas a la selección, delimitación y declaración de los denominados desde principios de siglo «espacios naturales protegidos», podremos verificar el olvido absoluto del territorio mariánico hasta hace veinte años. En efecto, ninguna de entre las figuras protectoras creadas en virtud de las sucesivas leyes y decretos emitidos desde 1916 (año de la pionera Ley de creación de Parques Nacionales), fue aplicada a paraje o enclave alguno de esta extensa y variada entidad espacial.

Tal carencia - sin dejar de ser ilustrativa de la deficiente historia española de la protección de la naturaleza - puede incluso comprenderse hasta los años setenta, teniendo presente que el balance de las primeras cinco décadas de política protectora había sido francamente pobre en España (MULERO, 1995); recordemos que, amén de Sierra Morena, quedaron marginadas otras grandes y significativas unidades geográficas del país. Las cifras son suficientemente ilustrativas de lo dicho: en 1970 se contabilizaban en todo el territorio español únicamente 103.007 hectáreas protegidas, es decir, el 0’2\% de la superficie estatal, distribuidas entre seis Parques Nacionales, dieciséis Sitios Naturales y un Monumento Natural. Sólo tres de estos espacios se localizaban en Andalucía y ninguno de ellos con emplazamiento mariánico; claro que, a tenor de las cifras expuestas, lo excepcional hubiera sido contar con algún espacio protegido en este conjunto serrano.

No obstante, la nula consideración de Sierra Morena continuó durante las actuaciones protectoras iniciadas en los años setenta, y esto sí que resulta sintomático de la pobre percepción que, desde las instancias medioambientales — científicas y políticas-, se ha tenido respecto del norte de Andalucía hasta fechas muy recientes. En dichos años se aplicaron renovados instrumentos para impulsar la deficiente política protectora española, concretados esencialmente en la creación del ICONA y de la Ley de Espacios Naturales Protegidos de 1975. Este último fue un texto ambicioso, por cuanto con él se pretendía mejorar la red española de espacios protegidos en un sentido cuantitativo pero también cualitativo. Se trataba de lograr una completa representación de los principales ecosistemas hispanos, para lo que se establecieron cuatro figuras protectoras complementarias y eficaces que, con ligeros retoques, han pervivido hasta nuestros días: Parque Nacional, Parque Natural, Paraje Natural y Reserva Integral. Con ellas se amplió sustancialmente el territorio estatal protegido respecto de la situación de 1970, aunque, paradójicamente, durante los casi quince años de vigencia de la citada ley no prosperó ninguna iniciativa protectora en el espacio que nos ocupa; ni siquiera se llegó a emplear la figura de Parque Natural, que con tanta profusión fue aplicada poco tiempo después, como tendremos ocasión de señalar en páginas posteriores.

\section{El cambio de orientación en los años ochenta: la percepción de Sierra Morena como espacio a proteger}

Dos grandes hitos tienen lugar en Andalucía durante los años ochenta, provocando un giro importante en la protección de su medio natural y, a la vez, en el papel que Sierra Morena va a desempeñar en la nueva situación; nos estamos refiriendo a la redacción de 
los Planes Especiales de Protección del Medio Físico y a la promulgación de la conocida como Ley del Inventario de Espacios Protegidos (Ley 2/1989, de 18 de julio).

\subsection{Los Planes Especiales de Protección del Medio Físico (P.E.P.M.F.)}

A comienzos de la década, la asunción progresiva de competencias en materia de ordenación del territorio, urbanismo y conservación de la naturaleza, supondrá inmediatamente la adopción de actuaciones dirigidas a reforzar la débil protección del medio natural andaluz hasta la fecha.

En este contexto, la primera intervención decidida y ambiciosa partió de la Consejería de Política Territorial de la Junta de Andalucía, que ya en 1982 encomendó a la Dirección General de Urbanismo la redacción de Planes Especiales de Protección del Medio Físico, de ámbito provincial. La necesidad de los mismos se justificó alegando que ni la legislación ambiental ni la ordenación territorial respondían en ese momento a las exigencias de la región en la materia, así como tampoco a lo estipulado en el artículo 45 de la Constitución. El instrumento seleccionado fue el Plan Especial, una figura de planeamiento recogida en la Ley del Suelo, a la que se consideró apropiada por su capacidad para regular los usos y las transformaciones del territorio y, en definitiva, poder alcanzar la pretendida protección del medio físico (SANZ, E. et al., 1982)

Los P.E.P.M.F. dotaron al territorio andaluz de una normativa de planeamiento urbanístico de ámbito provincial, regularon los usos y actuaciones a desarrollar en el medio físico, y establecieron en cada provincia un «Catálogo de Espacios y Bienes Protegidos». Unos catálogos que, en lo que concierne a Sierra Morena, constituyen la primera selección rigurosa de áreas naturales merecedoras de protección. Sin embargo, desde la perspectiva estricta de la salvaguarda del medio natural, estos instrumentos manifestaron inmediatamente grandes limitaciones: de una parte, porque se seleccionó un número excesivo de espacios en esta sierra (alrededor de setenta) y bajo diversas y heterogéneas categorías protectoras ${ }^{2}$; en segundo término, porque los espacios incluidos en el catálogo no fueron dotados de instrumentos específicos de ordenación, personal técnico o partidas presupuestarias dirigidas a su conservación y gestión, de manera que su incorporación al catálogo sólo les otorgó una protección jurídica añadida o complementaria a la que les brinda la legislación sectorial vigente, pero nada más. A la postre, este pionero intento de crear una red de espacios protegidos se ha revelado ineficaz, lo cual es también comprensible teniendo en cuenta que, en toda Andalucía, los ocho planes especiales aprobados incluyeron varios centenares de bienes y áreas protegidas, cuya enorme extensión hacía inviable cualquier pretensión protectora de mayor calado.

No es de extrañar, por lo tanto, la escasa repercusión que los catálogos de los P.E.P.M.F. han tenido, como tampoco el que administrativamente no se les considerara, llegado el momento, como alternativa idónea para conformar la red de espacios naturales protegidos que se pretendía crear en Andalucía. No obstante, algunos de ellos tuvieron utilidad como referente a la hora de proceder a la selección de aquellos espacios que, finalmente, integran la actual red andaluza de espacios protegidos.

2 Protección integral: Parajes Naturales Excepcionales; Zonas Húmedas; Yacimientos de Interés Científico. Protección compatible: Riberas Forestales de Interés Ambiental; Parajes Sobresalientes; Complejos Serranos de Interés Ambiental; Áreas Forestales de Interés Recreativo; Complejos Ribereños de Interés Ambiental; Paisajes Sobresalientes; Zonas Húmedas Transformadas; Paisajes Agrarios Singulares. 


\subsection{La Ley del Inventario}

En paralelo a la iniciativa descrita, en los ámbitos de influencia medioambiental — tanto científicos como políticos_-, se estaban asumiendo los nuevos planteamientos ideológicos que, durante la década anterior, se impusieron en los foros medioambientales internacionales -Estrategia Mundial para la Conservación de la Naturaleza; Informe de la Comisión Mundial sobre Medio Ambiente y Desarrollo (Informe Brutland); Programas Comunitarios sobre Medio Ambiente, etc.- Entre otras cosas, éstos postulaban la superación de las actuaciones políticas tradicionales basadas en intervenciones protectoras aisladas sobre territorios puntuales y sobresalientes por su «riqueza y variedad ecológica», con la única pretensión de conservar estáticamente sus condiciones naturales; a cambio propugnaban la difusión de acciones menos rígidas, que permitieran una mayor interacción entre el territorio objeto de protección y su entorno social y económico. Se trataba, en definitiva, de aunar la perspectiva ambiental con la planificación socioeconómica, de forma que ambas fuesen complementarias y no excluyentes: el concepto de ecodesarrollo se acuñó para expresar en síntesis los nuevos planteamientos, o sea, la superación de la clásica dicotomía entre conservación y desarrollo.

Desde este renovado horizonte se aspira a que amplios territorios andaluces dotados de una calidad ambiental contrastada, pero aquejados a la vez por una situación socioeconómica crítica, cuenten con políticas de intervención donde la conservación de los ecosistemas se convierta en pieza clave de la propia estrategia de desarrollo. Se trata de un presupuesto que, obviamente, conviene en general a las áreas de montaña y, de forma particular, a la extensa Sierra Morena.

De la misma manera, ha variado sustancialmente la percepción de la sociedad en relación con los espacios protegidos. La demanda de ocio y esparcimiento en contacto con la naturaleza ha crecido en paralelo a la intensificación de la urbanización, en un proceso común a la totalidad de los países desarrollados; pero también la sensibilidad y formación medioambiental del ciudadano español se ha incrementado de forma considerable, razón por la cual en los últimos años aquél se decanta claramente en sus preferencias por las áreas naturales de calidad, a las que identifica sobre todo con las que disponen de una figura de protección específica.

Finalmente, como respuesta a los nuevos retos que la ideología protectora y la sociedad plantean, se producen en Andalucía cambios administrativos y normativos de notable calado. En 1984 esta región recibe desde la administración central las competencias en materia de conservación de la naturaleza, lo que le permite iniciar, bajo la tutela de la recién creada Agencia de Medio Ambiente, una nueva andadura en pos de aplicar los renovados planteamientos ambientales. La actuación culminante de la primera etapa autonómica será la promulgación de la Ley 2/1989, de 18 de julio, por la que se aprueba el Inventario de Espacios Naturales Protegidos y se establecen medidas adicionales para su protección. Sin duda el nuevo texto regulador y la red de espacios que origina, reflejan ya lo esencial de una concepción distinta, cuyas aportaciones básicas pueden condensarse en los siguientes aspectos:

$1^{\circ}$. Las figuras protectoras se diversifican e incluso se amplian a partir de las contempladas en la ley estatal de conservación de espacios naturales (Ley 4/1989, de 27 de marzo). Se cuenta, en consecuencia, con figuras de distinta índole y desigual vocación protectora, las cuales permiten, por ejemplo, aplicar las tesis del ecodesarrollo en unas áreas, sin renunciar a la protección integral de aquellas otras en que ésta sea conveniente. Parque Nacio- 
nal, Reserva Natural, Paraje Natural, Paisaje Protegido, Monumento Natural, Parque Periurbano, Parque Natural y Reserva Natural Concertada, configuran un variado elenco, síntesis entre las propuestas estatal y autonómica que, a la postre, hace posible desechar las concepciones rígidas basadas exclusivamente en la protección de territorios-islas, nítidamente acotados y sin imbricación con su entorno.

$2^{\circ}$. Como continuación de lo anterior el territorio protegido se amplía sustancialmente hasta alcanzar el $17 \%$ de la superficie regional (casi 1'5 millones de hectáreas), si bien es cierto que la figura de Parque Natural es la elegida para cubrir más del $90 \%$ de tal extensión, convirtiéndose en la pieza clave de la nueva orientación protectora. Sin embargo, la función que ahora se encomienda a esta figura dista mucho de la que tuvo durante la vigencia de la ley de 1975; los espacios seleccionados para integrar la nueva red de 22 Parques Naturales son, en la mayoría de los casos, extensos y con una delimitación no concebida para otorgarles una protección férrea, sino más bien diseñada con la intención de ligar los problemas de conservación del medio con los problemas de desarrollo que aquejan a extensas áreas rurales, procurando fomentar, además, el uso público en las mismas. Sólo desde esta perspectiva puede entenderse que algunos de los actuales Parques Naturales abarquen comarcas enteras afectadas en los últimos decenios por una fuerte marginalidad económica y un claro despoblamiento. Como ya señalamos en otra ocasión la figura de Parque Natural se ha convertido en el «laboratorio» experimental donde ensayar la teoría del ecodesarrollo (MULERO, A., 1994 a y b).

$3^{\circ}$. El nuevo marco normativo no se limita - a diferencia de la anterior legislación protectora-, a establecer figuras y regular su declaración y sus reglas de funcionamiento interno. Como complemento se amplían los instrumentos de planificación (Plan de Ordenación de los Recursos Naturales; Plan Rector de Uso y Gestión; Plan de Desarrollo Integral; Programas de Fomento) desde el convencimiento de que, sin ellos, sería imposible la coordinación entre los tres grandes objetivos que la figura de Parque Natural pretende alcanzar: conservación de la naturaleza, desarrollo endógeno y fomento del uso público.

\section{La singularidad de la actuación mariánica: parques naturales y ecodesarrollo}

En realidad la existencia de una importante red de espacios naturales protegidos en Sierra Morena se debe a iniciativas muy recientes y aún no culminadas. En la década de los noventa este conjunto serrano ha pasado de ser un espacio minusvalorado y olvidado tradicionalmente en las políticas protectoras españolas, a convertirse en protagonista destacado de las mismas con más de medio millón de hectáreas protegidas. En principio la explicación de un cambio tan espectacular es bastante sencilla, considerando que tanto las tesis del ecodesarrollo como la figura de Parque Natural manifiestan una clara vocación hacia los espacios serranos - de ahí la sustancial ampliación de la protección también en las Cordilleras Béticas- Téngase en cuenta, por otra parte, el valor ambiental que mantienen determinados sectores de Sierra Morena, donde aún perviven numerosas especies de flora y fauna incluidas en el catálogo español de las amenazadas, así como extensos continuos vegetales con un alto grado de conservación. La variedad y riqueza de los paisajes naturales y culturales de esta amplia franja serrana justifica sobradamente el conjunto de actuaciones recientes dirigidas a su preservación (VALLE, 1999). Y si el anterior patrimonio se combina con una situación de precariedad socioeconómica y de franco retroceso y envejecimiento demográfico — resultado de la regresión de los sistemas agrarios tradicionales-, es indudable que nos encontramos en presencia del «caldo de cultivo» idóneo para 
implantar una nueva filosofía protectora que, como se ha dicho, pretende aunar conservación y desarrollo.

Es necesario tener presente lo anterior a la hora de interpretar la gestación de tan novedosa y extensa red de espacios protegidos, sus principales componentes geográficos y, asimismo, las profundas contradicciones latentes en ella, derivadas posiblemente de una ejecución precipitada y poco sopesada de las directrices teóricas iniciales. A continuación trataremos de forma somera algunos de los atributos básicos del territorio protegido en Sierra Morena.

\subsection{La red de espacios naturales protegidos en Sierra Morena: Expansión y protagonismo de los Parques Naturales}

Hoy encontramos una decena de espacios protegidos en la Sierra Morena andaluza, que abarcan una superficie total de 538.770 hectáreas (Cuadro $\mathrm{n}^{\circ}$ 1). Todos ellos han sido declarados el año 1989 mediante la Ley del Inventario, a excepción del Parque Periurbano de los Villares (Córdoba), cuya creación se hizo efectiva en el año siguiente.

El significado cuantitativo de lo protegido es ciertamente importante, por cuanto esta unidad geográfica reúne más del $36 \%$ de la superficie total que se protegió con la citada ley en Andalucía. Es verdad, no obstante, que estas cifras no tienen correspondencia en la diversidad de figuras utilizadas, desde el momento en que no existen Parques Nacionales, Reservas Naturales, Monumentos Naturales, Paisajes Protegidos o Reservas Naturales Concertadas, y el Parque Periurbano sólo se ha aplicado en una ocasión, a pesar de la extensa propiedad pública existente con vocación forestal y potencialidad recreativa. Esta escasa representatividad es una particularidad muy significativa de la red mariánica, pero sin duda el rasgo de mayor trascendencia es el protagonismo alcanzado por la figura de Parque Natural, que aparece bien representada en la franja serrana de las cuatro provincias implicadas y agrupa el $97 \%$ de lo protegido. Esta es la contundente razón por la que los Parques Naturales se han convertido en el centro de atención de la política protectora y de los trabajos de investigación actuales, eclipsando al resto de enclaves protegidos.

Es conveniente reparar en diversas características del sexteto de parques para aprehender en sus justos términos lo que ha supuesto su creación y su andadura en una década de existencia:

$1^{\circ}$. La protección de medio millón de hectáreas ha significado implicar en la nueva estrategia a 54 municipios serranos, varios de los cuales aportan la totalidad o la mayor parte de su término a un Parque Natural. En principio, por tanto, la trascendencia política y social de la actuación es clara y la participación de ayuntamientos, entidades sociales y población en general se torna completamente necesaria para llevar a buen puerto la apuesta protectora.

$2^{\circ}$. A pesar de que los seis Parques Naturales comparten un emplazamiento mariánico, la heterogeneidad entre ellos es la tónica dominante. Los contrastes son evidentes y muy diversos, aunque el más llamativo es una desigualdad en su extensión que se manifiesta, por ejemplo, al comparar las 6.000 hectáreas de Despeñaperros con las 184.000 de la Sierra de Aracena o las 164.000 de la Sierra Norte sevillana; algún parque tiene representación de un solo municipio (P.N. de Despeñaperros), en tanto que otro llega a reunir superficie correspondiente a 28 términos (P.N. de Aracena).

No es éste el momento de abundar en unas disparidades que se manifiestan también en los componentes físicos y bióticos de cada parque, en los criterios seguidos en cuanto a 
zonificación y normativa de funcionamiento, en los aprovechamientos y el tipo de propiedad dominante, etc. Baste señalar ahora la heterogeneidad como atributo de la red de parques, por cuanto los aspectos concretos de la misma serán objeto de nuestra atención posterior. Sin embargo, tengamos presente desde este instante que la clave de la profunda disparidad existente reside en el hecho de haber aplicado una misma categoría protectora — la de Parque Natural—, a espacios muy diferentes en los aspectos antes citados, lo que supone, en la práctica, comprometer a territorios de vocación opuesta en la consecución de los mismos objetivos, por lo demás muy ambiciosos.

$3^{\circ}$. Por último, en un contexto de grandes diferencias no podemos obviar una cuestión de fondo compartida por todos ellos, si bien con distinta intensidad: nos referimos al proceso de crisis que desde los años cincuenta se desencadenó en los sistemas agrarios de Sierra Morena, claramente traducido en un fuerte movimiento emigratorio, una tendencia al despoblamiento y envejecimiento demográfico y, finalmente, una situación de marginalidad económica y desarticulación territorial de extensos sectores serranos (RIVERA, 1992).

En esta realidad se basa uno de los argumentos esgrimidos por el planificador a la hora de justificar tan extensa actuación protectora, es decir: la necesidad imperiosa de dotar de nuevas alternativas a estos espacios rurales y el convencimiento de que ello puede lograrse mediante el fomento de un desarrollo sostenido canalizado a través de los Parques Naturales. En consecuencia resulta obligado proceder a comentar algunos de los indicadores socioeconómicos que manifiestan esta situación de estancamiento.

\subsection{Caracterización demográfica y socioeconómica de los Parques Naturales de Sierra Morena}

Los datos contenidos en el Cuadro $\mathrm{n}^{\circ} 2$ pueden ilustrarnos sobre la situación demográfica de los parques, con la advertencia de que se ha incluido la población municipal completa $-\mathrm{y}$ no sólo la que reside en el interior del perímetro protegido-, lo que reduce extraordinariamente su validez; téngase en cuenta que la gran mayoría reside en el área de influencia y que algunos parques son auténticos desiertos demográficos.

A pesar de lo anterior, de las cifras disponibles se deduce el diagnóstico de estancamiento demográfico a que aludíamos antes: en primer lugar, el contingente total de población es escaso (163.433 habitantes) ya que supone sólo el 17'7\% del peso demográfico de la red andaluza de parques, para un territorio protegido equivalente a más del $36 \%$ de la misma; este hecho se refuerza atendiendo a la densidad media de los distintos parques, inferior en todos los casos al promedio de la red andaluza (29'9 habs. $\left./ \mathrm{km}^{2}\right)$ y, por supuesto, muy alejada de la ocupación media que arroja la región en su conjunto (79 habs./Km²).

Igualmente importante es el hecho de que la población, amén de escasa, se encuentra muy envejecida y no alcanza los niveles formativos medios de los ámbitos de referencia (red andaluza de Parques Naturales y Andalucía). La tasa de envejecimiento de la población es alta y alcanza sus valores extremos en la Sierra de Aracena, Sierra Norte y Sierra de Cardeña y Montoro, y el nivel educativo apunta una situación de marginalidad que, siendo preocupante para el global de los parques andaluces (un 38\% de población de más de 10 años analfabeta o carente de estudios), es verdaderamente alarmante en los Parques de Sierra Morena, donde tal porcentaje se rebasa claramente.

En suma, los anteriores y otros indicadores demográficos complementarios son, en primer lugar, consecuencia del intenso movimiento emigratorio que siguió a la profunda crisis de la base productiva de estos espacios, de forma que, como refleja el Cuadro $n^{\circ} 2$, los 
municipios que conforman estos parques — con la excepción de Andújar- han perdido en treinta años (1960-1991) entre el 25\% y el 50\% de la población censada en ellos en 1960.

Por otra parte, los indicadores económicos básicos (desempleo y renta) que recoge el Cuadro $\mathrm{n}^{\circ} 3$ demuestran la situación de inferioridad de los parques serranos. Esta debilidad económica unida a la crisis demográfica justificó, a comienzos de los noventa, la conveniencia de ligar la política de conservación de la naturaleza con la promoción del desarrollo socioeconómico.

En relación con la situación económica, es necesario aclarar que, desde la creación de estos parques en 1989, la actuación pública de ayudas a la inversión y al desarrollo se ha canalizado mayoritariamente a través de programas gestionados por el Instituto de Fomento de Andalucía (IFA); y ello, dada la lamentable inexistencia de los Planes de Desarrollo Integral y de los Programas de Fomento, que son los instrumentos contemplados en la legislación protectora para llevar a la práctica las estrategias de ecodesarrollo. En consecuencia, las cifras disponibles sobre inversión económica en parques son las que ofrece el citado Instituto (Cuadro $\mathrm{n}^{\circ} 4$ ), datos que, curiosamente, la administración medioambiental ha esgrimido en ocasiones como prueba del éxito de la política de Parques Naturales, aún a sabiendas de su falsedad. Parece ignorarse que la incidencia de estas inversiones sobre los propios territorios protegidos es relativa y, en cualquier caso, mucho menor de lo que el montante financiero parece indicar. Esto es así porque el grueso de los proyectos empresariales y de la inversión ejecutada se ha centrado en sectores industriales y de servicios radicados generalmente en los núcleos urbanos del entorno protegido, viéndose favorecidas, en consecuencia, un conjunto de actividades que guardan poca o ninguna relación con la base económica de los parques serranos. Las inversiones auspiciadas por el IFA son, ante todo, un instrumento orientado al desarrollo económico general de éstos y otros municipios andaluces, y no una estrategia singular para el desarrollo sostenible de las áreas protegidas.

Es lamentable que tampoco se hayan creado las Gerencias de Promoción previstas, encargadas de coordinar todas las iniciativas de desarrollo en los Parques Naturales. Mientras no existan estos organismos no se alcanzará el impulso socioeconómico que han de conllevar los parques. Y, por otra parte, en su ausencia será imposible valorar las inversiones que recaen sobre los municipios de las áreas protegidas por su pertenencia a tales, y no por otras razones ajenas a la protección.

\subsection{La diversidad como atributo esencial de los Parques Naturales creados en Sierra Morena}

Como ya hemos apuntado en páginas anteriores, los Parques Naturales que se localizan en Sierra Morena tienen en común una situación de atraso socioeconómico y desarticulación territorial, pero a partir de ahí la diversidad funcional es la tónica dominante entre ellos; son profundas las diferencias en su relación con el entorno, en los criterios aplicados en su delimitación, y en su distinta vocación y funcionamiento en la actualidad.

\subsubsection{Distintas formas de relación con el entorno}

La percepción de homogeneidad que puede tenerse de estos parques, por mor de su pertenencia a una misma unidad geográfica, es sólo aparente. Entre ellos, podemos diferenciar, al menos, una triple tipología: 
a) El modelo de Despeñaperros, caracterizado por una reducida extensión, la participación de un solo municipio y la existencia de una bajísima densidad de población. Desde un punto de vista agrario los recursos existentes en el interior del Parque son escasos y generan débiles aprovechamientos forestales, ganaderos y cinegéticos, con escasa repercusión en la economía del entorno.

b) El modelo de las Sierras de Hornachuelos, Cardeña-Montoro y Andújar; espacios protegidos de superficie intermedia y marcados sobre todo por una orientación cinegético-forestal importante y un peso destacado de la gran propiedad. Lo anterior ha limitado la aparición de una red interior de asentamientos de consideración, lo que explica que hoy estos parques sean grandes vacíos humanos. Tampoco ha sido posible la gestación de unas actividades productivas con entidad suficiente como para tener relevancia en la dinámica económica de los municipios afectados, cuyo desarrollo en buena medida - con la excepción parcial de Cardeña- es bastante ajeno a lo que sucede en el interior del perímetro protegido; pensemos que los mayores municipios (Hornachuelos, Montoro y Andújar) tienen su núcleo emplazado en el Valle del Guadalquivir, y se encuentran más orientados hacia la actividad industrial y la agricultura.

c) El modelo de la Sierra de Aracena y de la Sierra Norte de Sevilla sobresale, de partida, por tratarse de espacios con una considerable extensión y numerosos municipios implicados, muchos de los cuales, a diferencia de los anteriores, tienen su emplazamiento en el interior del perímetro protegido. Así se entiende la importante presencia humana en el corazón de ambos parques, en contraste con la atonía demográfica propia de los restantes. Es muy fuerte, por otra parte, la vinculación entre población, desarrollo económico y recursos presentes en el parque; funcionan los ruedos de aprovechamiento agrícola en torno a los núcleos de población, perviven las formas de explotación tradicional del monte adehesado, con aprovechamiento extensivo del ganado y extracción de productos forestales, etc., a lo que se añade la transformación de estos productos por empresas radicadas en los núcleos del interior del parque o su entorno próximo. Todo esto se refleja en una clara imbricación entre actividades tradicionales, población local y espacio protegido que no existe en los modelos anteriores. Como tampoco se da en aquéllos la influencia que sobre la Sierra de Aracena y la Sierra Norte ejerce la capital regional: un fenómeno muy interesante en los últimos años ha sido el crecimiento del uso recreativo de estos parajes por parte de la población urbana sevillana, que en buena medida se ha convertido en propietaria y arrendataria de segundas residencias en la zona.

\subsubsection{Disparidad y fragilidad de los criterios utilizados en la selección y delimitación de los Parques Naturales}

Sin duda es éste otro aspecto singular y demostrativo de la heterogeneidad que encierra la red de parques serranos. Los titubeos y la disparidad de criterios en el momento de decidir qué se debía someter a protección, se perciben con claridad al contemplar y analizar el mapa de cada parque.

La polémica sobre los límites se manifiesta en distintos aspectos. Uno de los más ilustrativos quizás sea la utilización de un marco provincial y, por tanto, excesivamente artificial, a la hora de delimitar un espacio natural. De esta forma se ha impuesto una pretendida racionalidad administrativa — según la cual la gestión de aquéllos es más eficaz si se lleva 
a cabo desde una sola Delegación Provincial— en perjuicio de la racionalidad ecológica que hubiera aconsejado la creación de parques interprovinciales. Es evidente, por ejemplo, la continuidad natural y paisajística entre el sector oriental del parque de la Sierra Norte y el parque de la Sierra de Hornachuelos, e igualmente existe clara uniformidad entre los parques de la Sierra de Cardeña y Montoro y de la Sierra de Andújar, etc. Tanto es así que para este último la propuesta inicial del año 1987 (Agencia de Medio Ambiente, 1987) abogaba por la creación de un único parque de 89.000 hectáreas entre Jaén y Córdoba, con eje central en el Valle del Río Yeguas.

Sin embargo el problema no se originó exclusivamente por la circunstancia de que cada Parque debiera gestionarse por una sola Delegación Provincial y, en consecuencia, sus límites hubieran de quedar circunscritos al ámbito provincial. Por el contrario, la cuestión nuclear radicó en el trasfondo de aquello, a saber:

$1^{\circ}$. A mediados de los ochenta, desde los departamentos provinciales competentes, aún se tenía una idea muy desigual de la protección y de lo que debía ser un Parque Natural. Se trata de un asunto que no es ajeno a la formación y procedencia de los gestores y técnicos que se hicieron cargo de esta nueva competencia autonómica (por ejemplo, la concepción del biólogo frente a la del ingeniero de montes o agrónomo).

$2^{\circ}$. Por otra parte, la voluntad política se decantó por evitar que ninguna provincia andaluza quedara sin parque y, además, por conseguir que la superficie protegida en cada una estuviera equilibrada con las restantes, en la medida de lo posible. Desde este presupuesto cabe entender la gran extensión de los Parques Naturales de Huelva y Sevilla respecto de los demás, resultado de compensar la circunstancia de que ambas provincias cuenten sólo con uno, frente a los tres de Córdoba o los cuatro de Jaén. Este criterio de equilibrio provincial dio lugar, entre otras cosas, a la rectificación de la propuesta inicial de creación de un parque en la Sierra de Aracena con apenas 32.289 hectáreas (Agencia de Medio Ambiente, 1987), que poco después sería ampliado hasta las 184.000 hectáreas que ahora tiene.

\subsubsection{Una gestión desigual orientada por objetivos distintos}

La realidad que hoy encontramos en los Parques Naturales de Sierra Morena es que, partiendo de los objetivos generales propios de esta figura protectora, en la práctica cada uno ha optado por una orientación propia, acompañada por una gestión también singular. Como ya hemos tenido ocasión de tratar (MULERO, A., 1999b), los criterios de selección y delimitación de los espacios a proteger han sido heterogéneos e incluso contradictorios en ocasiones. El resultado se evidencia en la existencia de Parques Naturales netamente distintos, concebidos desde dos posturas básicas:

a) La primera, de índole más conservacionista, diseñó unos parques donde la primacía la ostentan los valores faunísticos, botánicos y paisajísticos; la conservación del medio es el objetivo básico, en detrimento de las demás funciones de esta figura protectora (ecodesarrollo y uso público). En consonancia con este presupuesto, se excluyeron del perímetro protegido aquellas áreas consideradas de inferior calidad ambiental (repoblaciones forestales, por ejemplo), así como todos los núcleos de población de cierta importancia,para evitar una presencia humana que pudiera alte- 
rar el estado de los ecosistemas de mayor valor. Este tipo de orientación se ha impuesto en el Parque Natural de la Sierra de Hornachuelos y, en menor medida, en los de Cardeña-Montoro y Andújar.

Esta intencionalidad conservacionista nos permite entender hoy dos asuntos clave: en primer lugar, que a sus promotores no les haya preocupado especialmente que la mayor parte de la superficie protegida tenga un régimen de propiedad privada (más del $90 \%$ de media para los tres parques), y, en segundo término, que los documentos planificadores aprobados (Plan Rector de Uso y Gestión y Plan de Ordenación de los Recursos Naturales) estén presididos por la salvaguarda y mejora de los ecosistemas, con una zonificación muy rígida y unas normas de uso y actividades poco permisivas con los cambios de aprovechamiento o con el fomento de las actividades de ocio.

b) El diseño de los Parques Naturales de la Sierra de Aracena y Sierra Norte de Sevilla obedeció a presupuestos distintos. En ellos se incorporó un extenso territorio de una calidad ambiental muy dispar, incluyéndose numerosos núcleos de población, así como espacios de tradicional vocación turístico-recreativa y fuerte presión antrópica. La ordenación de los aprovechamientos tradicionales, la divulgación del patrimonio, el fomento del turismo verde, etc. se encuentran entre las actuaciones prioritarias de los gestores de este tipo de parques. La conservación de los valores naturales siendo importante no es excluyente, ni siquiera prioritaria y, en consecuencia, el PRUG y el PORN diseñados son bastantes diferentes y más flexibles que los aprobados para otros parques emplazados en la misma unidad geográfica.

En tales términos de diversidad se sitúa hoy la red de Parques Naturales de Sierra Morena, cuya interpretación se presta a una doble lectura. Si la valoración parte de considerar a los seis parques en su conjunto, no cabe duda de que la distinta orientación que mantienen es un indicador de complementariedad muy interesante y positivo, por cuanto la mayor eficacia conservacionista de unos territorios se ve complementada con el mayor impulso al desarrollo o con la vocación turístico-recreativa de otros.

Sin embargo, si consideramos a cada parque como entidad individual que ha de lograr alcanzar por sí misma y su entorno los objetivos que la legislación ha encomendado a esta categoría protectora, nos encontramos un balance claramente insuficiente, por cuanto ninguno de ellos ha logrado aunar e impulsar de forma satisfactoria la conservación de la naturaleza, el desarrollo sostenible y el fomento del uso público. Precisamente el enjuiciamiento desde esta segunda perspectiva deparó, en 1994, un dictamen preocupante del Parlamento de Andalucía sobre la situación de los Parques Naturales; aquél consistió en un conjunto de recomendaciones con las que se pretendía - a juicio de la comisión encargada de su redacción- solucionar las deficiencias detectadas en estos espacios. La lectura de las mismas, cuya síntesis recogemos a continuación, viene a confirmar algunas de las carencias y contradicciones que hemos venido apuntando en las páginas precedentes:

$1^{a}$. En relación con el ecodesarrollo, el dictamen del Parlamento instó a culminar el proceso de planificación y, especialmente, los Planes de Desarrollo Integral. Asimismo manifestó la necesidad de crear en cada parque natural las Gerencias de Promoción, encargadas de coordinar las iniciativas de desarrollo. Ninguno de los Parques Naturales de Sierra Morena dispone, tras una década de existencia, de tales instrumentos. 
$2^{\text {a }}$. En lo concerniente a los problemas derivados de la delimitación y las diferencias en la gestión, que antes comentábamos, el Parlamento insistió con buen criterio en la necesidad de avanzar en la gestión unitaria de aquellos Parques Naturales contiguos que forman parte de una misma unidad natural; y se señaló la posibilidad de hacerlo en los parques de Sierra Morena occidental (Sierra de Aracena, Sierra Norte y Sierra de Hornachuelos) y en los de Sierra Morena oriental (Sierra de Cardeña-Montoro y Sierra de Andújar). En nuestra opinión esta pretensión se torna inviable de mantenerse el modelo rígido de administración provincial aplicado hasta el momento.

$3^{\text {a }}$. Por lo que respecta a la participación social e institucional en el funcionamiento de los parques, el dictamen recomendó incrementar las funciones de las Juntas Rectoras en este campo. De esta consideración puede colegirse que, ya hace un quinquenio, era manifiesta la escasa operatividad del máximo órgano de gestión de los parques; una deficiencia evidente en los emplazados en Sierra Morena que, además, lejos de subsanarse ha empeorado en los últimos años.

$4^{\mathrm{a}}$. Finalmente preocupó también el fomento del uso público. En unos casos porque determinados parques han conocido un incremento de la demanda que hace necesaria una respuesta más eficaz en oferta de servicios e infraestructuras; en otros el problema es la carencia de tradición recreativa y la imposibilidad de auspiciarla por la inexistencia de terrenos públicos y, en consecuencia, de oferta de actividades de ocio. En este terreno, la recomendación del grupo de expertos se situó en la línea de favorecer iniciativas empresariales privadas que asuman la promoción y gestión de los equipamientos y servicios de uso público; en Sierra Morena, aunque éstas se han incorporado, lo han hecho de forma débil y desigual.

\section{Las nuevas perspectivas: directiva Hábitats y creación del corredor ecológico de Sierra Morena}

Aún sin haberse concluido el proceso de consolidación de la red de Espacios Naturales Protegidos a cargo de la Consejería de Medio Ambiente, una nueva iniciativa, con pretensiones distintas, viene a ampliar sustancialmente el territorio sometido a protección en Sierra Morena. En este caso el impulso proviene de las instituciones comunitarias, mediante el desarrollo de la Directiva Hábitats (Directiva 92/43/CEE, relativa a la conservación de los hábitats naturales y de la flora y fauna silvestres), cuyo objetivo básico consiste en crear una red coherente de Zonas de Especial Conservación (ZEC), que garantice la biodiversidad en el territorio de la Unión Europea. Con esta intención, los Estados miembros deben presentar a la Comisión un listado de ámbitos a los que se denomina Lugares de Interés Comunitario (LIC), de cara a crear finalmente una gran red europea o Red Natura 2000 (MULERO, 1999a).

Estas propuestas, aunque con cierto retraso respecto a las previsiones iniciales, hoy se encuentran bastante avanzadas y, entre otras, la correspondiente a Andalucía está concluida. Cuando finalice el proceso completo de declaración, la región contará con 127 Lugares de Interés Comunitario, con una superficie total de 2.413.935 hectáreas, lo que supone el $27^{\prime} 7 \%$ del territorio andaluz, si bien es cierto que el $64{ }^{\prime} 8 \%$ de esa extensión corresponde a espacios naturales que ya están protegidos formando parte de la red vigente (aunque no todos los que la integran han sido considerados de interés comunitario); en consecuencia, la nueva iniciativa afectará a 809.038 hectáres que no se encuentran actualmente sometidas a ningún tipo de protección (el $35{ }^{\prime} 2 \%$ de la propuesta global). 
En Sierra Morena, las repercusiones de esta nueva iniciativa protectora son especialmente importantes por dos razones:

$1^{\mathrm{a}}$. Se han catalogado como Lugares de Interés Comunitario todos los espacios protegidos ya existentes (recogidos en el Cuadro $n^{\mathbf{0}} 1$ ), con la única excepción del Parque Periurbano de Los Villares. A éstos se añaden otros nueve enclaves con una superficie total de 366.100 hectáreas, es decir, el $45 \%$ del nuevo territorio a proteger en Andalucía (Cuadro $n^{\circ}$ 5). Sin duda esta iniciativa viene a confirmar el interés y las expectativas actuales que, en política de conservación de la naturaleza, concita esta unidad geográfica.

$2^{a}$. Las nuevas propuestas han incidido especialmente en la Sierra Morena cordobesa y jiennense y se han efectuado con la intención de conectar los espacios protegidos ya existentes. La finalidad no es otra que lograr crear una extensa franja protegida que, a modo de corredor ecológico, discurra sin interrupción entre los límites oriental y occidental de la Sierra Morena andaluza, abarcando más de 900.000 hectáreas. Se trata, en definitiva, de una actuación sin precedentes en nuestro país, aunque evidentemente es pronto para evaluar su viabilidad y eficacia.

\section{Bibliografía}

AGENCIA DE MEDIO AMBIENTE/CONSEJERÍA DE MEDIO AMBIENTE: Medio Ambiente en Andalucía. Sevilla, Consejería de Medio Ambiente, Publicación anual desde 1987.

MULERO MENDIGORRI, A. (1994 a): «La política de Parques Naturales en Andalucía: retos de una gran extensión territorial». Actas del VII Coloquio de Geografía Rural. Comunicaciones. Córdoba, A.G.E.-Universidad de Córdoba, 417-423.

- (1994 b): «Consideraciones sobre la problemática actual de los Parques Naturales en Andalucía». Actas del VII Coloquio de Geografía Rural. Comunicaciones. Córdoba, A.G.E.-Universidad de Córdoba, 424-429.

- (1995): Espacios rurales de ocio. Significado general y análisis en la Sierra Morena cordobesa. Madrid, Ministerio de Agricultura, Pesca y Alimentación, Serie Estudios no 89,565 pp.

- (1999 a): Introducción al medio ambiente en España. Barcelona, Ariel, 254 pp.

- (1999 b): Los espacios naturales protegidos en Andalucía: Evolución, caracterización geográfica y singularidades. Ería, Dpto. de Geografía, Universidad de Oviedo, en prensa.

POSADA, J.C. y CAMARA, R. (1990): «Territorio y protección de la naturaleza en Andalucía: Ley de Julio de 1989». Revista de Estudios Andaluces, no 14, pp. 57-92.

RIVERA MATEOS, M. (1992): Explotación agraria y ocupación del espacio productivo en Sierra Morena. Córdoba, Universidad de Córdoba (Serie Estudios de Geografía, $\left.\mathrm{n}^{\mathrm{o}} 5\right), 134 \mathrm{pp}$.

SANZ, E. et al. (1982): «Planes y políticas de protección de medio físico y gestión de recursos naturales». Estudios Territoriales, no 5 , pp. 79-92.

VALLE BUENESTADO, B (1999): «Sierra Morena: De espacio Agrario a espacio protegido». En: Libro Homenaje al prof. D. Jesús García Fernández, Universidad de Valladolid, en prensa. 


\section{Cuadro 1}

CATÁLOGO DE ESPACIOS NATURALES PROTEGIDOS EN SIERRA MORENA (1999)

\begin{tabular}{|c|c|c|c|c|}
\hline $\begin{array}{l}\text { Nombre del } \\
\text { espacio }\end{array}$ & $\begin{array}{l}\text { Figura } \\
\text { protectora }\end{array}$ & $\begin{array}{l}\text { Superficie } \\
\text { (Has.) }\end{array}$ & Provincia & Términos municipales \\
\hline Peñas de Aroche & $\begin{array}{l}\text { Paraje } \\
\text { Natural }\end{array}$ & 718 & Huelva & Aroche \\
\hline $\begin{array}{l}\text { Sierra Pelada y } \\
\text { Rivera del Aserrador }\end{array}$ & $\begin{array}{l}\text { Paraje } \\
\text { Natural }\end{array}$ & 12.980 & Huelva & $\begin{array}{l}\text { Rosal de la Frontera, } \\
\text { Aroche, Cortegana }\end{array}$ \\
\hline Cascada de Cimbarra & Paraje Natural & 534 & Jaén & Aldeaquemada \\
\hline $\begin{array}{l}\text { Sierra de Aracena } \\
\text { y Picos de Aroche }\end{array}$ & Parque Natural & 184.000 & Huelva & $\begin{array}{l}\text { Alájar, Almonaster la Real, Aracena, } \\
\text { Aroche, Arroyomolinos de León, } \\
\text { Cala, Cañaveral de León, Castaño } \\
\text { del Robledo, Cortaconcepción, } \\
\text { Cortegana, Cortelazor, Cumbres de } \\
\text { Enmedio, Cumbres Mayores, } \\
\text { Cumbres de San Bartolomé, } \\
\text { Encinasola, Fuenteheridos, Galaroza, } \\
\text { Higuera de la Sierra, Hinojales, } \\
\text { Jabugo, Linares de la Sierra, } \\
\text { Los Marines, La Nava, Puerto Moral, } \\
\text { Santa Ana la Real, Santa Olalla del } \\
\text { Cala, Valdelarco, Zufre. }\end{array}$ \\
\hline $\begin{array}{l}\text { Sierra Norte de } \\
\text { Sevilla }\end{array}$ & Parque Natural & 164.840 & Sevilla & $\begin{array}{l}\text { Alanís, Almadén de la Plata, Cazalla } \\
\text { de la Sierra, Constantina, } \\
\text { Guadalcanal, Las Navas de la } \\
\text { Concepción, El Pedroso, La Puebla } \\
\text { de los Infantes, El Real de la Jara, } \\
\text { S. Nicolás del Puerto. }\end{array}$ \\
\hline $\begin{array}{l}\text { Sierra de } \\
\text { Hornachuelos }\end{array}$ & Parque Natural & 67.202 & Córdoba & $\begin{array}{l}\text { Almodóvar del Río, Córdoba, Posadas, } \\
\text { Hornachuelos, Villaviciosa. }\end{array}$ \\
\hline $\begin{array}{l}\text { Sierra de Cardeña } \\
\text { y Montoro }\end{array}$ & Parque Natural & 41.212 & Córdoba & Cardeña, Montoro. \\
\hline Sierra de Andújar & Parque Natural & 60.800 & Jaén & $\begin{array}{l}\text { Baños de La Encina, Villanueva } \\
\text { de la Reina, Andújar. }\end{array}$ \\
\hline Despeñaperros & Parque Natural & 6.000 & Jaén & Santa Elena \\
\hline Los Villares & $\begin{array}{l}\text { Parque } \\
\text { Periurbano }\end{array}$ & 484 & Córdoba & Córdoba. \\
\hline
\end{tabular}

FUENTE: Consejería de Medio Ambiente (Junta de Andalucía). Elaboración propia. 
Cuadro 2

INDICADORES DEMOGRÁFICOS DE LOS MUNICIPIOS INCLUIDOS EN LOS

PARQUES NATURALES DE SIERRA MORENA

\begin{tabular}{|c|c|c|c|c|c|}
\hline & $\begin{array}{c}\mathrm{N}^{\mathrm{o}} \text { de } \\
\text { habitantes }\end{array}$ & $\begin{array}{c}\text { Densidad } \\
\left(\mathbf{H a b s} . / \mathbf{K m}^{2}\right)^{*}\end{array}$ & $\begin{array}{l}\text { Evolución } \\
\text { 1960-91** }\end{array}$ & $\begin{array}{c}\text { Tasa de } \\
\text { envejecimiento }\end{array}$ & $\begin{array}{c}\text { Población } \\
\text { analfabeta y } \\
\text { sin estudios*** }\end{array}$ \\
\hline Sierra de Andújar & 51.811 & $29 ’ 7$ & $97 ’ 4$ & $61 ' 6$ & 39 \\
\hline $\begin{array}{l}\text { Sierra de Aracena y Picos } \\
\text { de Aroche }\end{array}$ & 42.402 & $15^{\prime} 1$ & $60{ }^{\prime} 8$ & $133 ’ 3$ & $46^{\prime} 9$ \\
\hline Sierra de Cardeña y Montoro & 12.122 & 11 & $57^{\prime} 4$ & $84^{\prime} 9$ & $51 ’ 7$ \\
\hline Despeñaperros & 1.087 & $7 ' 5$ & $52{ }^{\prime} 4$ & $52 ’ 4$ & 43 \\
\hline Sierra de Hornachuelos & 24.009 & 14 & $77^{\prime} 1$ & $57^{\prime} 3$ & $48^{\prime} 1$ \\
\hline Sierra Norte de Sevilla & 31.912 & $13^{\prime} 6$ & $56^{\prime} 5$ & $94 ’ 7$ & $48^{\prime} 9$ \\
\hline $\begin{array}{l}\text { Parques Naturales de } \\
\text { Andalucía }\end{array}$ & 923.483 & $29 ’ 9$ & $121^{\prime} 4$ & $71^{\prime} 9$ & $38^{\prime} 1$ \\
\hline Andalucía & 6.940 .522 & $79^{\prime} 5$ & - & $63^{\prime} 6$ & 34 \\
\hline
\end{tabular}

FUENTE: Consejería de Medio Ambiente (Junta de Andalucía). Elaboración propia.

* Las cifra de población empleadas se corresponden con el total de los residentes en municipios que aportan superficie al Parque en 1991. De haberse considerado sólo la población residente en el interior del espacio protegido las densidades resultantes serían mucho menores.

** $1960=100$.

*** Porcentaje de población analfabeta y sin estudios mayor de 10 años.

Cuadro 3

INDICADORES ECONÓMICOS DE LOS MUNICIPIOS INCLUIDOS EN LOS PARQUES NATURALES DE SIERRA MORENA (1991)

\begin{tabular}{|l|c|c|c|}
\hline & $\begin{array}{c}\text { Tasa de desempleo } \\
(\%)\end{array}$ & $\begin{array}{c}\text { Renta per cápita } \\
\text { (ptas./hab.) }\end{array}$ & $\begin{array}{c}\text { Renta por unidad } \\
\text { de superficie } \\
\text { (ptas./Ha.) }\end{array}$ \\
\hline Sierra de Andújar & $22^{\prime} 6$ & 717.108 & 287.359 \\
\hline Sierra de Aracena y Picos de Aroche & $30^{\prime} 9$ & 567.250 & 92.391 \\
\hline Sierra de Cardeña y Montoro & $26^{\prime} 4$ & 568.580 & 52.110 \\
\hline Despeñaperros & $40^{\prime} 5$ & 516.000 & 38.682 \\
\hline Sierra de Hornachuelos & $34^{\prime} 1$ & 607.173 & 64.272 \\
\hline Sierra Norte de Sevilla & $38^{\prime} 5$ & 526.432 & 74.337 \\
\hline Parques Naturales de Andalucía & $29^{\prime} 8$ & 625.300 & 265.401 \\
\hline Andalucía & $28^{\prime} 4$ & 704.000 & 564.697 \\
\hline
\end{tabular}

FUENTE: Consejería de Medio Ambiente (Junta de Andalucía). Elaboración propia. 
Cuadro 4

AYUDAS CONCEDIDAS POR EL INSTITUTO DE FOMENTO DE ANDALUCÍA A

PROYECTO EJECUTADOS EN LOS PARQUES NATURALES DE SIERRA MORENA (1998)

\begin{tabular}{|l|r|r|r|r|}
\hline & $\mathbf{N}^{\text {o de proyectos }}$ & $\begin{array}{c}\text { Cuantía de la } \\
\text { inversión }\end{array}$ & $\begin{array}{c}\text { Cuantía de las } \\
\text { ayudas concedidas }\end{array}$ & Empleos creados \\
\hline Sierra de Aracena y Picos de Aroche & 12 & 4.360 .409 & 858.250 & 35 \\
\hline Sierra de Cardeña y Montoro & 1 & 9.812 & 5.593 & 0 \\
\hline Sierra de Andújar & 22 & 5.372 .507 & 668.859 & 104 \\
\hline Sierra Norte de Sevilla & 6 & 2.019 .800 & 408.483 & 30 \\
\hline Sierra de Hornachuelos & 7 & 794.301 & 128.771 & 19 \\
\hline Parques Naturales de Andalucía & 446 & 163.931 .601 & 20.784 .130 & 1.882 \\
\hline
\end{tabular}

FUENTE: Instituto de Fomento de Andalucía. Elaboración propia.

Cifras de inversión y ayudas en euros.

Respecto de 1996 el número de proyectos y la inversión han sufrido una fuerte recesión. Aquel año el número de proyectos para toda Andalucía fue de 1.058, con una inversión de más de nueve mil millones de pesetas y la creación de 7.300 empleos.

\section{Cuadro 5}

PROPUESTA DE NUEVAS ÁREAS A PROTEGER EN SIERRA MORENA EN EL CONTEXTO DE LA DIRECTIVA HÁBITATS (LUGARES DE INTERÉS COMUNITARIO)

\begin{tabular}{|l|c|c|}
\hline Denominación & Provincia & Superficie (Hectáreas) \\
\hline Sierra de Santa Eufemia & Córdoba & $10.651,56$ \\
\hline Río Guadalmez & Córdoba & $10.585,16$ \\
\hline Suroeste de la Sierra de Cardeña y Montoro & Córdoba & $33.087,47$ \\
\hline Guadalmellato & Córdoba & $37.565,46$ \\
\hline Guadiato-Bembézar & Córdoba & $106.809,84$ \\
\hline Ríos Cuzna y Gato & Córdoba & 112,09 \\
\hline Río Guadamatilla y Arroyo del Tamujar & Córdoba & 136,39 \\
\hline Cuencas del Rumblar, Guadalén y Guadalema & Jaén & $160.644,85$ \\
\hline Sierra de Alanís & Sevilla & $6.508,07$ \\
\hline Total & & $366.100,89$ \\
\hline
\end{tabular}

FUENTE: Consejería de Medio Ambiente (Junta de Andalucía), 1999. 